\title{
Abrasion of 6 dentifrices measured by vertical scanning interference microscopy
}

\author{
Florence PASCARETTI-GRIZON ${ }^{1}$, Guillaume MABILLEAU ${ }^{1,2}$, Daniel CHAPPARD ${ }^{1}$
}

\author{
1- LUNAM University, Groupe Études Remodelage Osseux et bioMatériaux (GEROM - LHEA), Institut de Biologie en Santé, Centre Hospitalier Universitaire \\ d'Angers, Angers, France. \\ 2- LUNAM University, Service Commun d'Imagerie et Analyses Microscopiques (SCIAM), Institut de Biologie en Santé, Centre Hospitalier Universitaire \\ d'Angers, Angers, France.
}

Corresponding address: Daniel Chappard - GEROM - LHEA - Institut de Biologie en Santé - LUNAM Université - Centre Hospitalier Universitaire d'Angers - Angers - France - Phone: (33) 244688349 - Fax: (33) 244688351 - e-mail: daniel.chappard@univ-angers.fr

Submitted: March 6, 2013 - Modification: June 10, 2013 - Accepted: August 12, 2013

ABSTRACT

bjectives: The abrasion of dentifrices is well recognized to eliminate the dental plaque.
The aims of this study were to characterize the abrasive powders of 6 dentifrices ( 3
toothpastes and 3 toothpowders) and to measure the abrasion on a test surface by Vertical
Scanning Interference microscopy (VSI). Material and Methods: Bright field and polarization
microscopy were used to identify the abrasive particles on the crude dentifrices and after
prolonged washes. Scanning electron microscopy and microanalysis characterized the shape
and nature of the particles. Standardized and polished blocks of poly(methylmethacrylate)
were brushed with a commercial electric toothbrush with the dentifrices. VSI quantified
the mean roughness (Ra) and illustrated in 3D the abraded areas. Results: Toothpastes
induced a limited abrasion. Toothpowders induced a significantly higher roughness linked
to the size of the abrasive particles. One powder (Gencix ${ }^{\circledR}$ ) produced a high abrasion when
used with a standard testing weight. However, the powder is based on pumice particles
covered by a plant homogenate that readily dissolves in water. When used in the same
volume, or after dispersion in water, Ra was markedly reduced. Conclusion: Light and
electron microscopy characterize the abrasive particles and VSI is a new tool allowing the
analysis of large surface of abraded materials.

Keywords:Toothpaste. Toothpowder. Tooth abrasion. Interference microscopy. Surface properties.

\section{INTRODUCTION}

Since the ancient times, the incorporation of abrasive powder in toothpastes or powders has been done. Various abrasive materials have been proposed such as bone ash (which is mainly composed of $\beta$-tricalcium phosphate $\left.{ }^{3}\right)$, coral, shell, marble or pumice powders. These powders are hold either in suspension in a pasty thickening hydrogel containing a wetting agent in the case of toothpastes or mixed with other powders such as metal oxides, phosphates or plant extracts ${ }^{11}$. Several studies have been conducted to evaluate the abrasion of both dentifrices and toothbrush filaments ${ }^{8}$. It is classical in the dental literature to compare the abrasion of different types of toothpastes' formulations and in 1995, the ISO 11609 standard was proposed following the original works of Hefferen on Radioactive Dentine Abrasion $(\text { RDA })^{12}$. Briefly, permanent teeth from $<40$ y.o. subjects are used to prepare radioactive dentine specimens following ${ }^{32} \mathrm{P}$ irradiation. The specimen surfaces are then brushed with an electric toothbrush under standard procedures (time, tension...). The toothpastes are compared with values obtained with a reference abrasive (calcium pyrophosphate in an hydrogel composed of glycerol and carboxymethyl cellulose $)^{10}$. At the end of brushing, the slurries are vortexed and put in a scintillation counter for radiation detection and abrasion is expressed in count per minute divided by the weight of dentine sample. Because the method is difficult and requires health hazardous procedures, other techniques have been proposed such as contact or non-contact profilometry $^{1,22}$. 
The aims of the present study were 1) to characterize the abrasive powders entering in the composition of a variety of dentifrices by light and scanning electron microscopy ${ }^{13} ; 2$ ) to measure the abrasion of each formula on polished poly(methylmethacrylate) (PMMA) surfaces using Vertical Scanning Interference microscopy (VSI).

\section{MATERIAL AND METHODS}

\section{PMMA blocks}

PMMA blocks were prepared by using a purified monomer containing $1 \%$ of the polymerization accelerator benzoyl peroxide. $0.2 \%$ of the substituted amine $\mathrm{N}-\mathrm{N}$ dimethylaniline were added to initiate polymerization ${ }^{5}$. The accelerated and initiated mixture was poured in Peel-a-way embedding molds $(25 \mathrm{ml} / \mathrm{mold}$ - Polyscience Inc., Warrington, PA, USA) and polymerization took place in a cold environment $\left(+4^{\circ} \mathrm{C}\right.$ in a refrigerator with a water bath to limit the temperature peak). Because polymerization is not completed when the blocks have hardened, a one month period separated their preparation from further use ${ }^{17}$. Blocks were then ground on an automatic plane grinding machine Tegramin-30 (Struers, Copenhagen, Denmark) using ascending grads of polishing paper (1200, 2000 and 4000 during 2 min each). Final mirror polishing was made with a MD-Nap paper spray with DiaPro
$1 \mu \mathrm{m}$ solution. Polished PMMA blocks were affixed onto plastic slides with a hand-press (Struers) in order to have a perfectly horizontal surface parallel to the slide.

\section{The tooth brushing system}

A commercial electric toothbrush was used in this study (Oral- $B^{\circledR}$, Braun, France) with the following conditions: load of the toothbrush standardized at $250 \mathrm{~g}$ (verified with the internal pressure control of the brush), brushing time: 2 min (as recommended by the manufacturer); soft hardness toothbrush head, rotation sense changing every $30 \mathrm{sec}$. For each type of dentifrice, a new toothbrush was used after an overnight incubation in distilled water. The toothbrush head was in direct contact with the PMMA block and the dentifrice. For the toothpastes, $0.2 \mathrm{~g}$ were weighted on a high precision scale, diluted in $500 \mu \mathrm{l}$ of distilled water and applied directly on the PPMA block with a syringe. For one of the powder (Gencix ${ }^{\circledR}$ ) with a very low mass-weight, the volume used appeared considerable (more than a pea: trial "Gencix ${ }^{\circledR}$ full volume") and a smaller volume (similar to those used with the other powders) was used in an additional trial (trial: "Gencix ${ }^{\circledR}$ reduced volume"). A third trial was done according to the manufacturer instructions where the toothbrush is soaked in powder-containing water as follows: a volume of toothpaste equivalent to a pea (i.e.

\begin{tabular}{|c|c|c|c|c|c|}
\hline Name & $\begin{array}{c}\text { Mass density } \\
\left(\mathrm{g} / \mathrm{cm}^{3}\right)\end{array}$ & Main components & Conservative & Abrasive & stain \\
\hline Parodontax ${ }^{\circledast}$ & 2 & $\begin{array}{c}\text { Plant extracts (rathania, myrrha, } \\
\text { chamomilla, mentha, salvia) } \\
\text { glycerol, cocamidopropyl betain, } \\
\text { alcohol }\end{array}$ & Na benzoate & Na bicarcarbonate & Iron Oxide \\
\hline Denivit ${ }^{\oplus}$ & 1 & $\begin{array}{c}\text { Sorbitol, propylene glycol, } \\
\text { pentasodium triphosphate, } \\
\text { cellulose gum, PEG } 60 \text {, castor } \\
\text { oil, NaF, Na saccharin }\end{array}$ & Methylparaben & $\begin{array}{l}\text { Hydrated silica, } \\
\text { Aluminum oxide }\end{array}$ & $\mathrm{TiO}_{2}(\mathrm{Cl} 77891)$ \\
\hline $\begin{array}{l}\text { Colgate } \\
\text { Total }^{\circledR}\end{array}$ & 1.33 & $\begin{array}{c}\text { Glycerol, sorbitol, Na lauryl } \\
\text { sulfate, } \mathrm{PVM} / \mathrm{MA} \text { copolymer, } \\
\text { limonene, } \mathrm{NaF}, \mathrm{NaOH}, \mathrm{Na} \\
\text { saccharin, cellulose gum, } \\
\text { carrageenan }\end{array}$ & Trichlosan & Hydrated silica & $\mathrm{TiO}_{2}(\mathrm{Cl} 77891)$ \\
\hline Per Blan ${ }^{\circledR}$ & 1.25 & $\begin{array}{c}\text { Plant extracts (chamomilla, } \\
\text { salvia, melissa, hamamelis, } \\
\text { potentilla, rosmarinus, } \\
\text { glycyrrhiza, aloe, citrus) xylitol, } \\
\text { Na methyl cocoyl taurate, } \mathrm{NaCl}\end{array}$ & none & Ca Carbonate & none \\
\hline Kontrol $^{\circledR}$ & 1 & $\begin{array}{c}\text { Sorbitol, Na lauryl sulfate } \\
\text { mentha, PVP, Na undecylenate, } \\
\text { Na saccharin, dimethicone }\end{array}$ & Methylparaben & $\begin{array}{l}\text { Dicalcium } \\
\text { phosphate }\end{array}$ & none \\
\hline Gencix $^{\circledast}$ & 0.66 & $\begin{array}{c}\text { Plant homogenate (Carica } \\
\text { papaya) }\end{array}$ & none & Pumice powder & none \\
\hline
\end{tabular}

Figure 1- Composition of the 6 dentifrices (3 toothpastes, 3 toothpowders) studied 
$\sim 100 \mathrm{mg}$ of the powder was dissolved in $1 \mathrm{ml}$ of distilled water). The toothbrush was soaked into the mixture, then applied to the surface of the PMMA block (trial: "Gencix ${ }^{\circledR}$ diluted"). For each dentifrice, the experiment was conducted 3 times on 3 different blocks. A control was done in triplicate with a new toothbrush moistened with $500 \mu$ l of distilled water.

\section{The dentifrices}

Three toothpastes were investigated: Colgate Total $^{\circledR}$ (Unilever, Rueil-Malmaison, France); Denivit ${ }^{\circledR}$ (Schwartzkopf \& Henkel, Boulogne-Billancourt, France), Parodontax ${ }^{\circledR}$ (Glaxo-Smith-Kline GSK, Marly-le-Roi, France). Three toothpowders were analyzed in parallel: Kontrol ${ }^{\circledR}$ (Omega Pharma, Chatillon, France); Per Blan ${ }^{\circledR}$ (Per Blan, Paris, France) and Gencix ${ }^{\circledR}$ (Esprit d'Ethique, Nantes, France). The raw composition of each dentifrice (as provided by the manufacturers) appears on Figure 1 together with its mass density. For each dentifrice, an analysis was conducted by light and electron microscopy. First, a small amount of paste or powder was placed on a microscopic glass slide, covered with a thin glass lamella and imaged by bright field illumination. Then, $0.5 \mathrm{~g}$ of each dentifrice was dissolved in 10 $\mathrm{ml}$ of distilled water and stirred for $5 \mathrm{~min}$ with a magnetic stirrer to dissolve all the organic/inorganic soluble components. The mixture was centrifuged, the supernatant was discarded and the residue was washed several times with distilled water. Finally, a drop of the residue was placed on a glass slide as previously. Light microscopy was performed on an Olympus BX51 microscope (Olympus, Rungis, France) using bright field and polarized light illumination at a magnification of 100x. Residues were also placed on a brass stub, carbon-coated by sputtering (10 $\mathrm{nm}$ thick) and analyzed with a Zeiss EVO LS10 scanning electron microscope (Carl Zeiss Ltd, Nanterre, France) equipped with an energy $\mathrm{X}$-ray microanalysis system (INCA XMAX, Oxford Instruments, Oxford, UK) to determine the atomic composition of the non-soluble abrasive component.

\section{The Vertical Scanning Interference microscopy (VSI)}

Measurements were done using a Wyko NT 9100 vertical scanning interference microscope (Bruker Nano Surface, Palaiseau, France), a system originally dedicated to the measurement of roughness in material samples. VSI is based on light interferometry and operates as a non-contact optical profiler in vertical scanning mode to produce 3D topography maps of the sample surface. Briefly, a white light source is emitted by conventional light source and is split into two beams which pass through a Mirau's interferometry objective. The incident beams are reflected from the reference mirror and the sample surface respectively. The light reflected from this

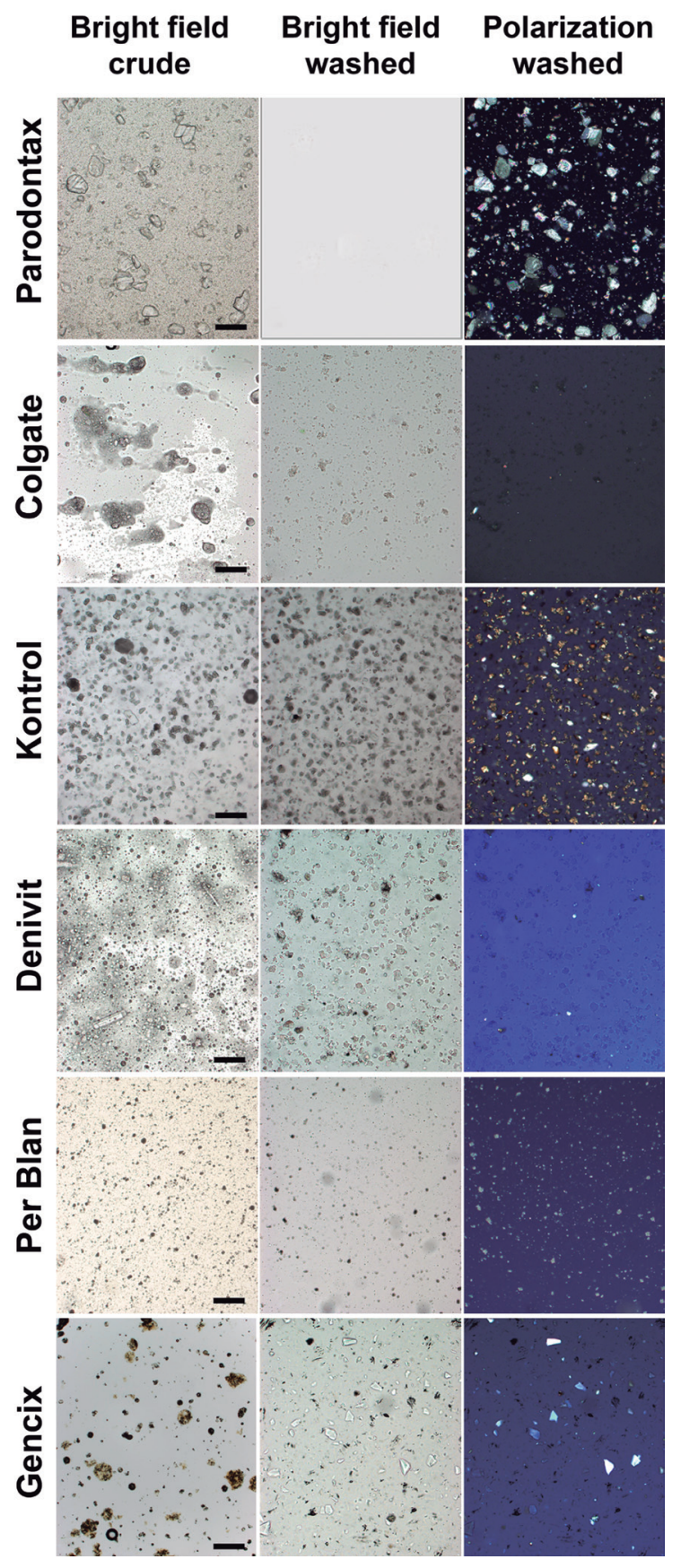

Figure 2- Light microscopic aspect of the six dentifrices studied at the same magnification (100x; the bar stands for $200 \mu \mathrm{m})$. For each of them, the image of the 1st column corresponds to the appearance of the crude dentifrice under glass slide and coverslip in bright field microscopy. The $2^{\text {nd }}$ column corresponds to the abrasive powder obtained after extensive washes and examined under glass slide and coverslip in bright field microscopy. Note the considerable differences in size and shape of the particles. In the $3^{\text {rd }}$ column, the same field is examined in polarized light to see the aspect of the abrasive powder (excepted for Parodontax ${ }^{\circledR}$, whose abrasive particles were dissolved during the washing steps, the image correspond to the polarization aspect of the $1^{\text {st }}$ column). Note that abrasive particles can be birefringent or not 
mirror combines with the light reflected from the sample to produce interference fringes (known as interferogram) where the best-contrast fringe occurs at best focus. The light and dark fringes are used in combination with the wavelength of the light to determine height difference between each fringe. A piezo-electric stage moves the sample vertically with a nanometer precision, which produces phase shifts in the interferogram. Interferograms were digitized using a CCD camera and data were analyzed to produce topographic surface maps at a magnification of $5 x$. For each block, 3 images $(1.0 \times 1.3 \mathrm{~mm})$ were obtained in the 4 quadrants of the brushed surface (internal, medium and outer position). The software
Vision $^{\mathrm{TM}}$ (release 4.10, Wyco) was used to acquire the data and compute the mean roughness ( $R a$, expressed in $\mu \mathrm{m}$ ) on each image. For each block, the values were averaged on the 12 images and the mean value obtained on the 3 blocks was considered; so for each trial, the analyzed surface was $46.8 \mathrm{~mm}^{3}$.

\section{Statistical analysis}

Statistical analysis was performed using the Systat statistical software release 13.0 (Systat Software Inc., San José, CA, USA). All data were expressed as mean \pm standard deviation. Differences between groups were analyzed by a non-parametric ANOVA test (Kruskall-Wallis) with the Conover-
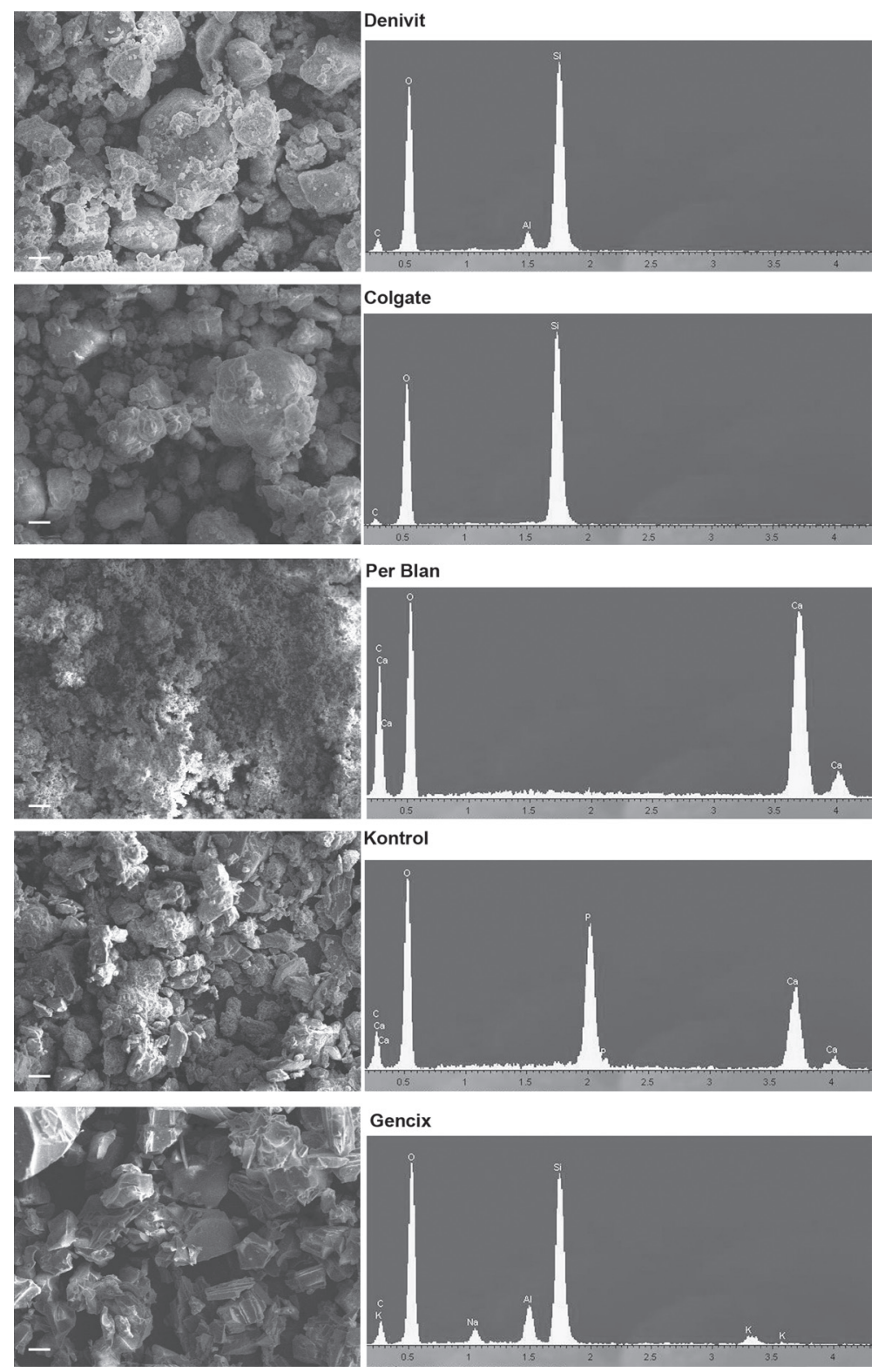

Figure 3- Scanning electron microscopy of the abrasive grains contained in the different types of dentifrices and obtained after extensive washing and centrifugation. The EDX spectrum of each type of particle appears on the right. All images were obtained at the same magnification $(500 \mathrm{x})$ and the white bar stands for $10 \mu \mathrm{m}$. Note the considerable differences in shape and composition of the abrasive particles contained in the six dentifrices. The $\mathrm{NaHCO}_{3}$ particles of Parodontax ${ }^{\circledR}$, having being solubilized during the preparation steps, are not figured 
Inman post-hoc test. Differences were considered significant when $\mathrm{p}<0.05$.

\section{RESULTS}

\section{Light microscopy}

The light microscopy aspect of the different dentifrices appears on Figure 2. All dentifrices contained inorganic particles used as abrasive but the size of the grains considerably differed between them. The larger grains were observed for Parodontax ${ }^{\circledR}$ and the smaller for Colgate Total ${ }^{\circledR}$ and Per Blan ${ }^{\circledR}$. Dilution and washing of the different dentifrices was used to separate and enrich the slurry in these abrasive particles from the other components. However, the highly soluble grains of sodium bicarbonate contained in Parodontax ${ }^{\circledR}$ were completely dissolved. Polarization microscopy identified birefringent and non birefringent characteristics of the abrasive powders. Some dentifrices (Colgate Total ${ }^{\circledR}$, Gencix ${ }^{\circledR}$, Denivit $\left.^{\circledR}\right)$ appeared to be composed of both types of particles. Others (Per Blan ${ }^{\circledR}$ and Kontrol ${ }^{\circledR}$ ) contained only birefringent ones. The $\mathrm{NaHCO}_{3}$ particles of Parodontax ${ }^{\circledR}$ were birefringent in the undiluted phase.

\section{Scanning electron microscopy}

The image of the different types of abrasive grains appears on Figure 3 for all dentifrices (except Parodontax ${ }^{\circledR}$, in which the particles were dissolved during the preparation steps). The EDX analysis confirmed the presence of silicate particles only in Colgate Total ${ }^{\circledR}$. Calcium oxide was evidenced in Per Blan ${ }^{\circledR}$ as a fine deposit. Calcium phosphate constituted all the particles of Kontrol ${ }^{\circledR}$; Denivit ${ }^{\circledR}$ contained both silicates and aluminum oxides and the Gencix ${ }^{\circledR}$ particles coming from pumice were composed of sodium and potassium silicates together with traces of aluminum oxides.

\section{VSI analysis}

The surface of each PMMA block exhibited signs of abrasion even when the brush was used with distilled water. Typical images of eroded surfaces are illustrated in Figure 4. The statistical results for the surface roughness parameter $\mathrm{Ra}$ of the different dentifrices are graphically presented in Figure 5. Ra did not differ significantly between toothbrush without dentifrice and with Parodontax ${ }^{\circledR}$ or Gencix ${ }^{\circledR}$ used in reduced volume. Denivit ${ }^{\circledR}$ and Colgate Total ${ }^{\circledR}$ produced significantly higher erosion (resp. $\mathrm{p}<0.006$ and $\mathrm{p}<0.002$ ). The toothpowders were associated with a significant higher Ra than the different toothpastes or the brush alone $(p<0.0001)$ except Gencix ${ }^{\circledR}$, used in reduced volume. Considerable differences exist when using the different modes for using Gencix ${ }^{\circledR}$ and the full volume trial induced the marked abrasion.

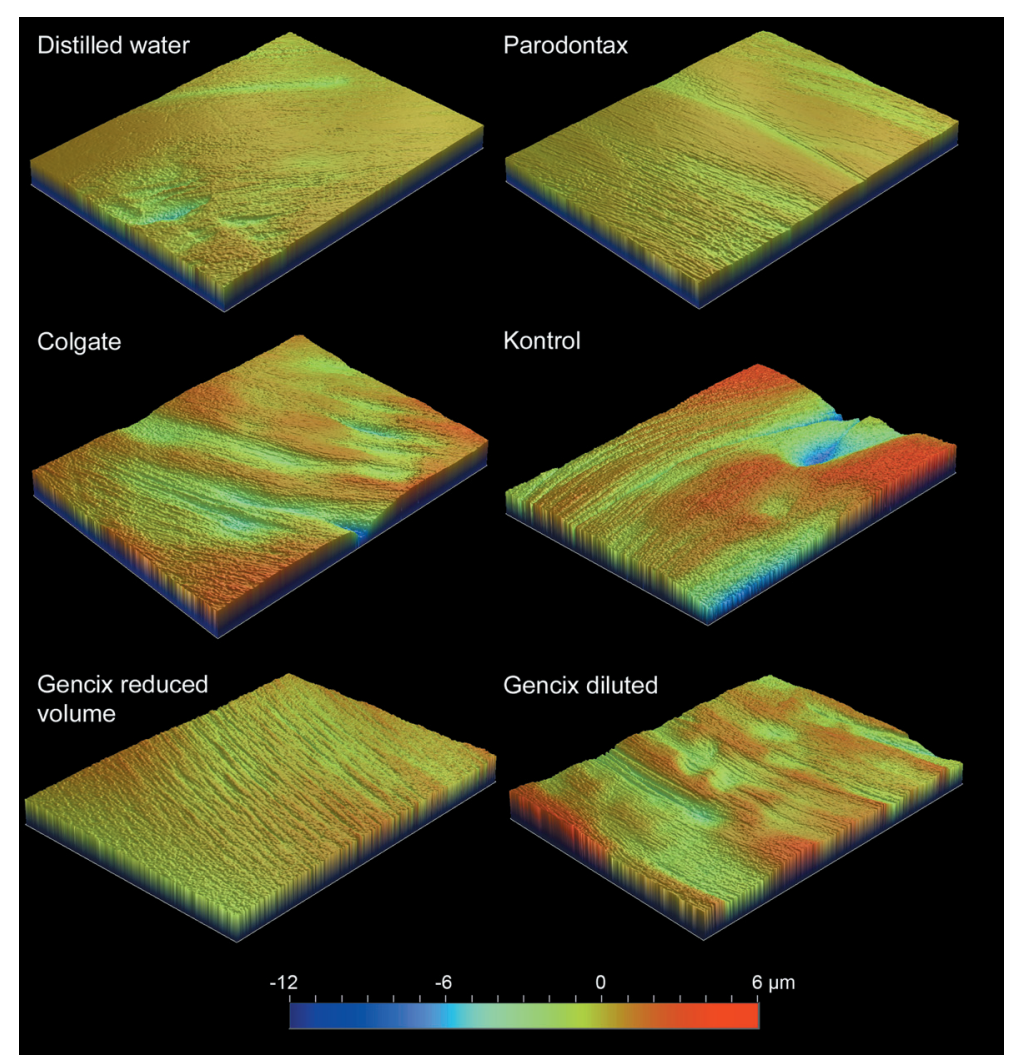

Figure 4- Vertical scanning interference microscopy of the surface of PMMA blocks after brushing with different types of dentifrices. Each image corresponds to a $1 \times 1.3 \mathrm{~mm}$ surface area. The colored scale bar (ranging from -12 to $+6 \mu \mathrm{m}$ ) represents the abrasion depth 


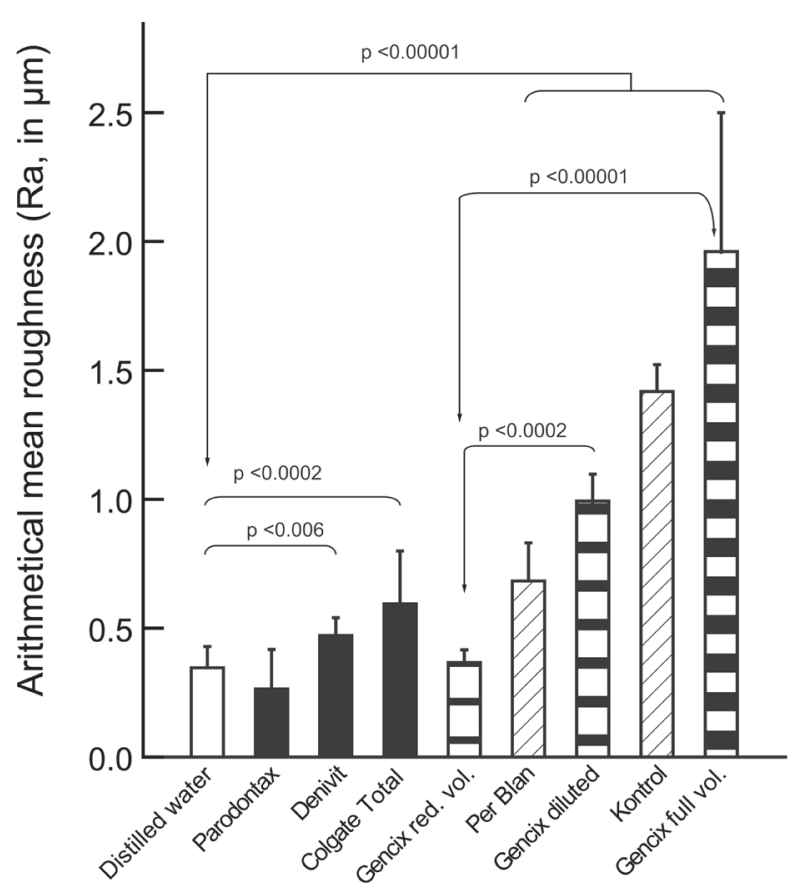

Figure 5- Surface roughness analysis after brushing with the different dentifrices. Bars correspond to the average value obtained on the 3 blocks analyzed per dentifrice (12 images per block). Data are expressed as mean \pm standard deviation. Toothbrushes used with distilled water: white bar; with toothpastes: black bars; with toothpowders: patterned bars. The different ways of using Gencix ${ }^{\circledR}$ appear with different types of horizontal patterned bars

\section{DISCUSSION}

The aims of the present study were to analyze the abrasive powders contained in 6 different dentifrices ( 3 pastes and 3 powders) and to evaluate their abrasive capacity on a synthetic polymer - PMMA widely used in dentistry.

It is well recognized that the capacity of a dentifrice to abrade can be attributed to the nature and size of its particulate abrasive components ${ }^{20,25}$. Here, we found that Parodontax ${ }^{\circledR}$, which contains large grains of sodium bicarbonate, did not produce a significantly rougher surface than the brush used with distilled water alone. It is likely that the high and rapid solubility in water of this compound (mainly used as a whitening agent that is fully soluble in water) had no significant effect on abrasion ${ }^{15}$. Bright field microscopy revealed that all grains were rapidly dissolved in water and could not be observed by polarization microscopy or SEM. Denivit ${ }^{\circledR}$ and Colgate Total $^{\circledR}$ which contained some insoluble abrasive grains had a low but significantly higher abrasion on PMMA blocks. All toothpowders which contained insoluble abrasive grains were associated with a significantly higher effect than the control brushes with either distilled water or toothpastes. A limitation of the present study is that the hardness of individual grains could not be determined. We were unsuccessful when trying to measure this parameter by nanoindentation due to the small size of individual grains and the impossibility to firmly anchor them for this type of analysis. It is likely that pumice powder grains are harder than calcium phosphate or calcium carbonate particles and the nature of the grain influences the abrasive powder 20,25 .

The tooth brushing test was performed as recommended by the toothbrush manufacturer and it used the control system incorporated in the electric device to control the pressure and time of analysis. These parameters are those recommended in daily use $^{4,24}$. However, only a single 2 min brushing was used here contrary to a number of studies where prolonged brushing times or cycles are used ${ }^{2,18,25-}$ 27,29 . This short brushing time was chosen because 1) PMMA is by far less hard than enamel or dentine (i.e. the Young's modulus is $3.1 \mathrm{GPa}$ and hardness 196 MPa for PMMA vs. $88 \mathrm{GPa}$ and 4,800 MPa for enamel; $22 \mathrm{GPa}$ and $800 \mathrm{MPa}$ for dentine) $)^{9,19}$; 2) VSI is a very accurate method used in industry to measure surface roughness of materials at the nanoscale level on larger surfaces than atomic force microscopy ${ }^{14}$; 3) PMMA is the major component of denture which are also cleaned by brushing $2,6,7,20,23,25$. In addition, PMMA-based polymers are also used in veneers or soft liners which can also be abraded by dentifrices ${ }^{16}$.

We found that VSI provided reliable quantitative results and was able to image the surface of the material together with providing arithmetic mean roughness. The method has been used in only one paper to calculate Ra but no images were presented ${ }^{22}$. The toothbrush moistened with distilled water alone appeared to cause a limited abrasion of the polymer. It has previously been reported that the rigidity of the brush's bristles can influence the abrasion of synthetic acrylic polymers ${ }^{26,28}$. Because all brushes used in this study were of the same model and only new brushes were used for each dentifrice, the abrasion due to the dentifrice itself is the real reason to produce additional scars at the surface of PMMA blocks. When the same weight of toothpaste was used, the abrasion noted on the PMMA blocks appeared roughly related to the size of the abrasive particles evaluated by bright field and polarization microscopy. However, as specified by the manufacturer, the Gencix ${ }^{\circledR}$ powder should not be used as a classical toothpowder. The pumice particles are mainly used to nucleate and facilitate the deposit of the plant homogenate and produce spherical capsules. As the plant homogenate is readily dissolved in water, only the pumice particles (composed of silicates and aluminum oxide) with sharp edges are liberated. So, when the test is done with a large amount of powder, this leads to the accumulation of a considerable volume of pumice 
powder. When using the Gencix ${ }^{\circledR}$ toothpowder as recommended by the manufacturer (after dilution in water), the abrasion was in the same range than Per Blan ${ }^{\circledR}$ or Kontrol ${ }^{\circledR}$. Because the mass density of the dentifrice is lower than the other powders, using the same volume of Gencix ${ }^{\circledR}$ powder did not produce significant erosion when compared to the brush used with distilled water or Parodontax ${ }^{\circledR}$.

\section{CONCLUSION}

Bright field and polarization microscopy, together with SEM analysis, are simple methods to evaluate the morphology of the abrasive particles contained in a dentifrice, although these methods are only qualitative. VSI microscopy is a new powerful technique for the evaluation of material and biomaterial surface and to study their degradation at the nanoscale level ${ }^{19,21}$. The technique allows both quantitative and qualitative evaluation of roughness. Abrasion due to a dentifrice appears linked to the amount and nature of the abrasive powder used.

\section{ACKNOWLEDGMENTS}

This work was made possible by grants from Contrat Region Pays de la Loire: Bioregos2 program. Many thanks to Mrs. Lechat for secretarial assistance.

\section{CONFLICT OF INTEREST}

\section{Authors have no conflict of interest.}

\section{REFERENCES}

1- Addy M. Determination of relative dentifrice abrasivity to enamel and dentine by a surface profile method. J Clin Dent. 2010;21:S13-4.

2- Ambjørnsen E, Holland RI. In vitro abrasion of two acrylic veneers. Dent Mater. 1994;10:107-10.

3- Balmain N, Legros R, Bonel G. X-ray diffraction of calcined bone tissue: a reliable method for the determination of bone $\mathrm{Ca} / \mathrm{P}$ molar ratio. Calcif Tissue Int. 1982;34(Suppl 2):S93-8.

4- Boyd RL, McLey L, Zahradnik R. Clinical and laboratory evaluation of powered electric toothbrushes: in vivo determination of average force for use of manual and powered toothbrushes. J Clin Dent. 1997;8:72-5.

5- Chappard D, Palle S, Alexandre C, Vico L, Riffat G. Bone embedding in pure methyl methacrylate at low temperature preserves enzyme activities. Acta Histochem. 1987;81:183-90.

6- Freitas KM, Paranhos HFO. Weight loss of five commercially available denture teeth after toothbrushing with three different dentifrices. J Appl Oral Sci. 2006;14:242-6.

7- Freitas-Pontes KM, Silva-Lovato $\mathrm{CH}$, Paranhos HFO. Mass loss of four commercially available heat-polymerized acrylic resins after toothbrushing with three different dentifrices. J Appl Oral Sci. 2009;17:116-21.

8- Garcia FCP, Wang L, D'Alpino PHP, Souza JB. Evaluation of the roughness and mass loss of the flowable composites after simulated toothbrushing abrasion. Braz Oral Res. 2004;18:156-61.
9- Giráldez de Luis I, Garrido MA, Gómez-del Río T, Ceballos L, Rodríguez J. Comparison of the mechanical properties of dentin and enamel determined by different nanoindentation techniques: conventional method and continuous stiffness measurement. Bol Soci Española Cerám Vidrio. 2010;49:177-82.

10- González-Cabezas C. Determination of the abrasivity of dentifrices on human dentin using the radioactive (also known as relative) dentin abrasion (RDA) Method. J Clin Dent. 2010;21:S9-10. 11- Hefferren J]. Historical view of dentifrice functionality methods. J Clin Dent. 1998;9:53-6.

12- Hefferren J]. A laboratory method for assessment of dentrifrice abrasivity. J Dent Res. 1976;55:563-73.

13- Leite FRM, Capote TSO, Zuanon ACC. Application of the total etching technique or self-etching primers on primary teeth after air abrasion. Braz Oral Res. 2005;19:198-202.

14- Li Q, Gao H, Shifu Xue S, Li H, . Optical profilometer based on the principle of differential interference. Optical Engineering. 2001;40:833-6.

15- Lima DANL, Faria e Silva AL, Baggio Aguiar FH, Liporoni PCS, Egberto Munin, Ambrosano GMB, et al. In vitro assessment of the effectiveness of whitening dentifrices for the removal of extrinsic tooth stains. Braz Oral Res. 2008;22:106-11.

16- Mainieri VC, Beck J, Oshima HM, Hirakata LM, Shinkai RS. Surface changes in denture soft liners with and without sealer coating following abrasion with mechanical brushing. Gerodontology. 2011;28:146-51.

17- Moreau MF, Chappard D, Lesourd M, Montheard JP, Baslé MF. Free radicals and side products released during methylmethacrylate polymerization are cytotoxic for osteoblastic cells. J Biomed Mater Res. 1998;40:124-31.

18- Moretto MJ, Magalhães AC, Sassaki KT, Delbem ACB, Martinhon CCR. Effect of different fluoride concentrations of experimental dentifrices on enamel erosion and abrasion. Caries Res. 2010;44:135-40.

19- N'Diaye M, Pascaretti-Grizon F, Massin P, Baslé MF, Chappard D. Water absorption of poly(methyl methacrylate) measured by vertical interference microscopy. Langmuir. 2012;28:11609-14.

20- Panzeri H, Guimaraes LEH, Paranhos HDO, da Silva CHL, de Souza RF, Gugelmin MCMD, et al. In vitro and clinical evaluation of specific dentifrices for complete denture hygiene. Gerodontology. 2009;26:26-33.

21- Pascaretti-Grizon F, Mabilleau G, Baslé MF, Chappard D. Measurement by vertical scanning profilometry of resorption volume and lacunae depth caused by osteoclasts on dentine slices. J Microsc. 2011;241:147-52.

22- Philpotts $\mathrm{CJ}$, Weader $\mathrm{E}$, Joiner $\mathrm{A}$. The measurement in vitro of enamel and dentine wear by toothpastes of different abrasivity. Int Dent J. 2005;55:183-7.

23- Pisani MX, Bruhn JP, Paranhos HFO, Silva-Lovato CH, Souza RF, Panzeri $\mathrm{H}$. Evaluation of the abrasiveness of dentifrices for complete dentures. J Prosthodont. 2010;19:369-73.

24- Pugh BR. Toothbrush wear, brushing forces and cleaning performances. J Soc Cosmetic Chem. 1978;29:423-31.

25- Richmond R, Macfarlane TV, McCord JF. An evaluation of the surface changes in PMMA biomaterial formulations as a result of toothbrush/dentifrice abrasion. Dent Mater. 2004;20:124-32.

26- Sorgini DB, da Silva-Lovato $\mathrm{CH}$, de Souza RF, Davi LR, Paranhos HFO. Abrasiveness of conventional and specific denture-cleaning dentifrices. Braz Dent J. 2012;23:154-9.

27- Tanoue N, Matsumura H, Atsuta M. Wear and surface roughness of current prosthetic composites after toothbrush/dentifrice abrasion. J Prosthet Dent. 2000;84:93-6.

28- Teche FV, Paranhos HF, Motta MF, Zaniquelli O, Tirapelli C. Differences in abrasion capacity of four soft toothbrushes. Int J Dent Hyg. 2011;9:274-8.

29- Wiegand A, Otto YA, Attin T. In vitro evaluation of toothbrushing abrasion of differently bleached bovine enamel. Am J Dent. 2004; $17: 412-6$. 